JICA

27,2

\title{
Editorial
}

98

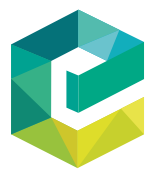

Journal of Integrated Care Vol. 27 No. 2, 2019 pp. $98-99$

C) Emerald Publishing Limited $1476-9018$

DOI 10.1108/JICA-04-2019-070

\section{Does integrated care have a future?}

At a recent conference celebrating the success of a European integrated care project, a colleague commented that what struck him most about integrated care is that there has been so little progress made for patients. Looking back over more than two decades of work in the field, the most remarkable aspect, he thought, was that most of the problems that services struggled with at the very inception of the discipline were still with us, issues around data sharing, governance and interprofessional learning.

That is not to say that integrated care has not made enormous advances and produced tangible improvements. Increased multi-professional collaboration counts as one of the biggest gains brought about by integrated care initiatives and it is now well evidenced. Yet, the wider picture is one of dogged resilience of health systems in the face of the continuous onslaught of policies advocating service integration of one type or another. Why is that the case? Are we running out of steam on the integration front?

When I started to work in learning disabilities in 2005, the doyen of Welsh learning disabilities research, David Felce, remarked to me that "learning disabilities have had it". The English learning disabilities strategy "Valuing People" had been launched in 2001, following a sustained policy push on de-institutionalisation of people with intellectual disabilities. That, Felce believed, was "about it" for the next generation. Policy, he argued comes in waves, and by 2005 , the field had had more than its quota of policy attention.

If policy attention comes in waves, then integrated care is very lucky indeed. It has been at the centre of policy making for almost two decades now in health and social care. In fact, it has never been quite out of favour, if you count "partnership work" in the 1990s and the shift to multi-disciplinary teams in mental health provision in the 1980s as precursors of integrated care initiatives.

However, a slow but steady change in the wider narrative of integrated care policy is palpable. Where it was all about overcoming professional fragmentation in the 1990s and early 2000s, integrated care is now about addressing rising healthcare costs. Integrated care has morphed from a mechanism to mitigate the effects of interprofessional boundaries to a vehicle of fiscal prudence.

The old motives may still be with us. Improved collaborative practices make for better patient care, no doubt. Yet today, the main impetus for integrated care is the spiralling cost of care, and integration at times appears to be a panacea for bringing healthcare budgets under control.

Whilst the sustained policy attention afforded to integrated care may give us reasons to be cheerful, it has also engendered a curious response by services and practitioners. Integrated care is rarely something that they do, out of conviction and enthusiasm. It is, more likely than not, something that is done to them, introduced top-down.

In fact, integration is often mandated by central or local government, as an answer to prayers for more efficient services and for better care outcomes. This lack of bottom-up activity in integrated care has reasons, and it has consequences. As for the reasons, integrated care is fiendishly difficult to design, implement and evaluate. Its impact is often unclear for years, with tangible results only showing after many years of upfront investment. Which raises the question, why would any service manager embark on such a complex service improvement programme?

A consequence may be that, by now, pretty much everything under the sun is called "integration", leading to an inflation of claims, with little hard evidence to come by, and resulting in integration fatigue. 
And then, there are the bad apples. Where acute hospital trusts "integrate" community trusts into their provision, integrated care initiatives may in fact be genuinely detrimental to patient care outcomes. Services that were previously provided in the community may be arrogated by hospitals with adverse consequences for patients. In effect, the power of large hospital trusts often remains one of the biggest obstacles to shifting hospital provision into community care. No doubt, there are other examples where what looks like laudable service integration turns out to be a victory of organisational control over patient needs.

So what is the future of integrated care? More policy initiatives? Or, perhaps we should ask another question: if David Felce was right and policy attention is a finite resource in a democratic society, what is the source of political capital for future integrated care initiatives?

We may glean an answer to this question is we change perspective. If integrated care has so far benefited from strong policy support, which produced mainly top-down initiatives, revitalising integration must start by (re)discovering its original purpose, the patient. At the heart, integrated care carries a commitment to person-centred services. Although rarely realised in practice, person-centredness is probably the most powerful tool to transform services if utilised appropriately in service reforms. Whilst it requires herculean efforts by professionals, it can bring about lasting change.

There are two mechanisms that are likely to push person-centredness at the forefront of healthcare provision, which in turn will make integrated care the main conduit for service improvements.

The first is that patients are increasingly in the driving seat of their own care. Several developments contribute to this: increased accessibility of medical knowledge through the internet (a blessing and a curse to many clinicians), the need for better self-management of conditions due to cost pressures and the continuing need for informal care in the health economy. These factors conspire to encourage patients to resist conventional, paternalistic approaches in health systems.

The second is the development of big data which enables healthcare services to analyse health populations to an unprecedented level of granularity, down to individual patient level. Actuarial modelling of local healthcare data can now reveal to service planners and commissioners who is likely to have a heart attack in the next three months, and design system responses to individual needs.

The predictive power of population health data will have two consequences. First, where it can be used, it will have to be used. Care planners have a duty of care and it would not be long until there will be an obligation to design preventative care packages on the back of predictive modelling.

The second is that care planning will shift from being disease specific, encompassing large populations to focussing at patient level. Service responses to anticipated healthcare needs will require holistic care plans involving community health, housing and social care interventions requiring a different magnitude of collaboration between service providers.

Integrated care will be a critical component of services when trying to design adequate responses to these challenges of big data and increased patient involvement. So, policy may come and go, but the larger trends in healthcare will make integrated care inevitable. Although integrated care initiatives will change their nature under the auspices of big data and patient-driven care, they will be with us for the foreseeable future. And we, researchers and practitioners alike, need to prepare for it. 